\title{
Noise and Vibration Reduction - the Cranktrain as a Main Powertrain Module
}

\author{
P. Novotný* \& V. Píštěk \\ Institute of Automotive Engineering, Brno University of Technology, Brno, Czech Republic, \\ *Corresponding author: novotny.pa@fme.vutbr.cz
}

\begin{abstract}
This paper discusses how the multi-body dynamics approach combined with flexible body effects is being applied to predict the vibrations of crankshaft, bearing loads or cranktrain noise level due to structural flexibility. The oil film effects in the journal bearing are implemented with the use of a finite difference method. An application example of a Diesel inline four-cylinder engine is given in this paper to show this sophisticated simulation model and to predict the dynamic response of the flexible system and loads in the journal bearings.
\end{abstract}

KEY WORDS: noise, vibration, cranktrain, finite difference method, slide bearing model

\section{INTRODUCTION}

The efforts to reduce noise pollution in the urban environment and to satisfy the rising comfort demands, require low noise vehicle engines and power units. Thus comprehensive simulation methodologies and software tools are necessary during the design phase to analyze the complex physical events of noise generation and to transfer it to engines and power units.

The complex dynamics cranktrain model has been developed especially for these applications. It takes advantage of an outstanding simulation technology, which enables one to produce realistic results of engine dynamics and noise that are very close to the absolute ones.

For the design of internal combustion engines, the reliability of the cranktrain and slide bearings or the piston to liner contact is of central importance. Its design affects key functions such as durability, performance, wear and noise of the engine. Due to increasing specific loads, all physical effects have become important and they have to be taken into consideration by advanced simulation tools involving structural elasticity and dynamics.

\section{SOLUTION METHODS}

Finite element solutions show discrepancies as compared with the test dealing with dynamically loaded structures that undergo large rigid body motion. Such systems typically show geometric non-linearity and non-linear compliance between the different bodies. Solutions with the use of non-linear FEA have improved the accuracy of results yet have failed to provide a complete description of complex mechanical systems, including hydrodynamics and large rigid body motion. 
Multi-body dynamics with flexible bodies combine the advantages of a geometric non-linear FEA and rigid body dynamics. The modal synthesis method for flexible bodies superimposes flexible effects on rigid body motion. The multi-body dynamics approach, including the effects of flexible bodies based on the modal synthesis method, tracks frequencies in the $\mathrm{kHz}$ range accurately and applies forces, kinematic joints and constraints robustly. This approach properly updates the mass properties to account for the changes in, for example, location and inertia due to deformation at each time step, and takes into account the Coriolis and gyroscopic effects too.

During the simulation, the hydrodynamic forces are calculated at every time step as a function of the relative position and velocity of the reference nodes on the flexible crankshaft and the engine block. This approach employs the impedance method, where forces are calculated as results of the eccentricity and eccentricity rate.

The multi-body dynamics code, ADAMS, is used in this work. The basic premise of the ADAMS flexible body methodology is to use the multi-body dynamics equations of motion for a system of rigid bodies with algebraic constraints, and to include modal coordinates from finite element analyses. The modal synthesis method for flexible bodies is applied to superimpose flexible effects on rigid body motion. Experience has proved that static modes, combined with fixed boundary condition normal modes, provide the best dynamic solutions. This approach has the advantage of efficiency over pure finite element methods for modeling the structural dynamic response of mechanical systems undergoing large rotational motion.

\section{CRANKTRAIN MODEL}

The multi-body dynamic model of the complete powertrain is shown in Figure 1. An engine block is connected to the ground by bushing supports.

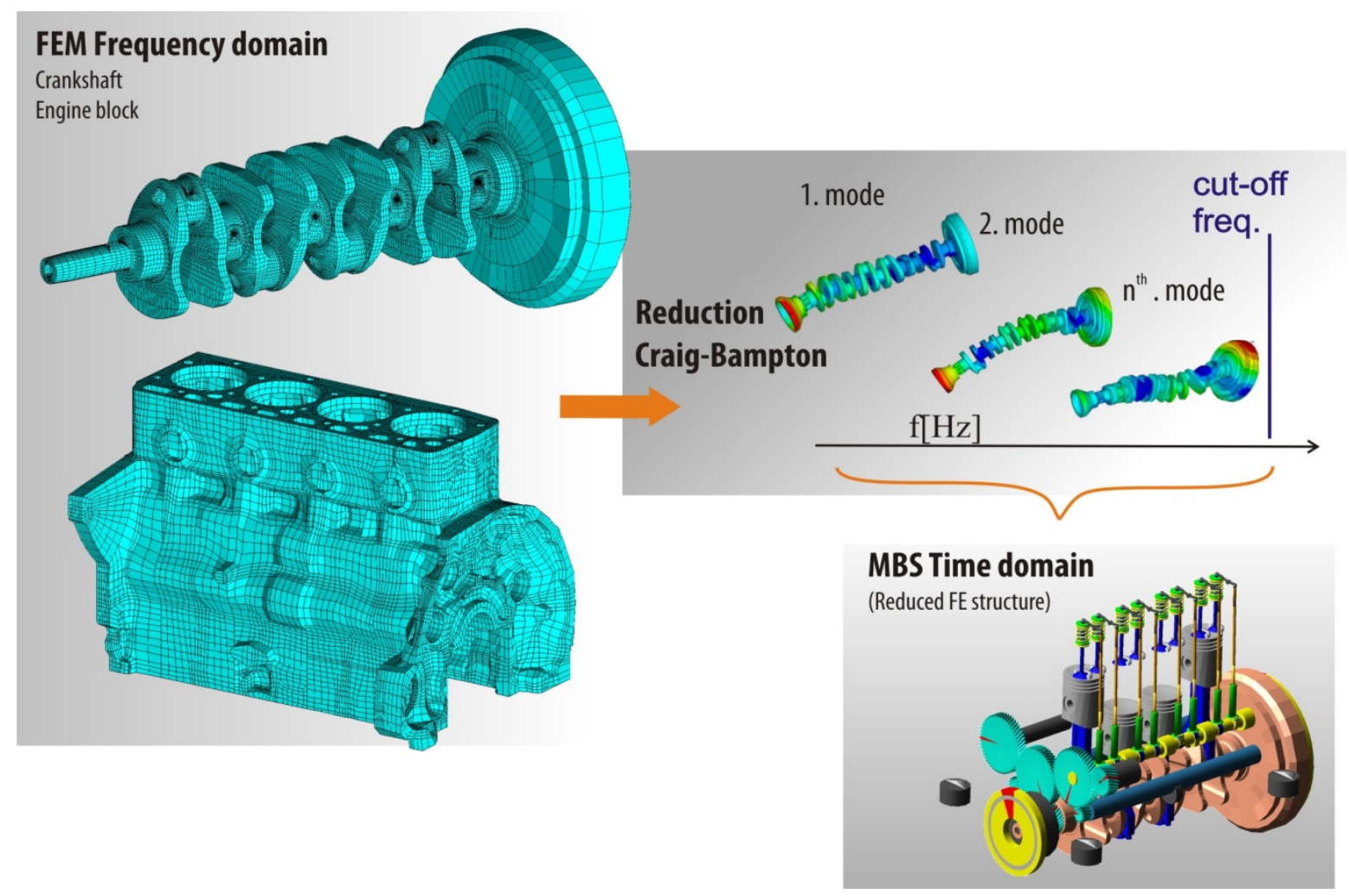

Figure 1: MBS model of powertrain with FE parts 
The crankshaft and the engine block are modeled as flexible bodies, while the connecting rods and pistons are modeled as rigid bodies. A simplified model for piston side load takes care of the interaction between the piston and the engine block. The remaining parts of the system kinematics are modeled with mechanical joints defined in ADAMS between the different bodies of the engine.

All modes up to $10000 \mathrm{~Hz}$ were extracted for the crankshaft. A set of 80 Craig-Bampton modes was used for the crankshaft. Likewise, all modes up to $10000 \mathrm{~Hz}$ were included for the engine block. This ensures a good representation of static and dynamic deformation. Gas forces were applied to the pistons and the combustion chambers. Static mode shapes were selected on the cylinder bore to account for piston side loads.

\section{SLIDE BEARING MODEL}

A slide bearing can be described as a sleeve around a pin with a lubricating fluid. The lubricant is supplied within a suitable slot. Tangential and radial motion, in combination with a wedged gap, generate a pressure in the oil film in the slide bearing. The bearing loading is periodical and the pin center passes through the bearing trajectory.

Modern specialized slide bearing codes are enabled to deal with various physical phenomena, for example elasticity of a shell or a journal (EHD), Goenka (1986), mixed boundary conditions, cavitation phenomena, Oujja (2006), or thermal and pressure dependent oil viscosity (TEHD) presented by Thomas (2007). All these features can be used if the main object of interest is the slide bearing itself. However, including the given features has a tremendous effect on computation times. These require an application of simpler HD codes for the global powertrain dynamics. The hydrodynamic solution is decoupled from the dynamic solution of MBS Solver. Therefore, the equations are solved for several bearing working conditions (eccentricities and tilting angles) prior to the dynamic analysis. The MBS bearing results (e.g. forces and moments) are consequently considered as input conditions for separate bearing solutions.

The dynamic behavior of hydrodynamic bearings is described by the well-known Reynolds's differential equation

$$
\frac{\partial}{\partial x}\left(h^{3} \frac{\partial p}{\partial x}\right)+\frac{\partial}{\partial z}\left(h^{3} \frac{\partial p}{\partial z}\right)=6 \eta\left(U \frac{\partial h}{\partial x}+2 \frac{\partial h}{\partial t}\right)
$$

$\begin{array}{lll}\text { where } & p & \text { is pressure } \\ t & \text { is time } \\ h & \text { is angle dependent bearing clearance } \\ \eta & \text { is dynamic viscosity } \\ U & \text { is effective velocity, and } \\ x, z & \text { are coordinates }\end{array}$

The Reynolds's equation (1) is transformed into a dimensionless form when applied to global powertrain dynamics. For the transformation details of Reynolds's equation see Butenschön (1976) or Rebbert (2000). 
In classic formulation [1], the angle dependent dimensionless bearing clearance $H$ is defined as

$$
H=1+\varepsilon \cos \varphi,
$$

where $\quad \varepsilon \quad$ is the relative eccentricity, and

$\varphi \quad$ is the angle about the axis of rotation

However, the above definition (2) does not include tilting effects and must be transformed into the following form

$$
H^{*}=H^{*}(\varphi, \gamma, \delta, \varepsilon)=H(1-\gamma Z \cos \varphi-\delta Z \sin \varphi)
$$

where $\quad Z \quad$ is the relative coordinate in the axis of rotation direction

$\gamma \quad$ is the first tilting dimensionless angle (for details see Figure 3), and

$\delta \quad$ is the second tilting dimensionless angle

Now, the definition of $H^{*}$ includes tilting effects and is inputted into the dimensionless Reynolds's equation.

The resultant differential equations describing the distribution of dimensionless pressure can be rewritten as

$$
\begin{aligned}
& \frac{\partial^{2} \bar{\Pi}_{V}}{\partial \varphi^{2}}+\left(\frac{D}{B}\right)^{2} \frac{\partial^{2} \bar{\Pi}_{V}}{\partial Z^{2}}+a(\varphi, \varepsilon, Z, \gamma, \delta) \bar{\Pi}_{V}=b_{V}(\varphi, \varepsilon, Z, \gamma, \delta), \\
& \frac{\partial^{2} \bar{\Pi}_{D}}{\partial \varphi^{2}}+\left(\frac{D}{B}\right)^{2} \frac{\partial^{2} \bar{\Pi}_{D}}{\partial Z^{2}}+a(\varphi, \varepsilon, Z, \gamma, \delta) \bar{\Pi}_{D}=b_{D}(\varphi, \varepsilon, Z, \gamma, \delta),
\end{aligned}
$$

where

$$
\Pi_{D}=\frac{p_{D} \psi^{2}}{\eta \bar{\omega}} \text { and } \quad \Pi_{V}=\frac{p_{V} \psi^{2}}{\eta \dot{\varepsilon}}
$$

and $\quad \bar{\Pi}_{V}, \bar{\Pi}_{D}$ are the dimensionless pressures for tangential and radial movements,
$D \quad$ is the bearing diameter
$B \quad$ is the bearing width
$\bar{\omega} \quad$ is the effective angular velocity
$\psi \quad$ is an independent bearing clearance
$\dot{\varepsilon} \quad$ is a time derivation of dimensionless eccentricity, and
$a, b_{V}, b_{D}$ are coefficients

The equation (4) describes oil pressure for the tangential movement of the journal and the equation (5) describes oil pressure for the radial movement of the journal. Both equations embrace the tilting effects.

The bearing model also includes the solution of cavitation phenomena. Cavitation usually occurs in the regions of diverging lubricated contact gap and implies sub-ambient pressures of the lubricant. These low pressures lead to a transformation of the liquid into a gas-liquid mixture; details are presented by Sahlin \& Almquist (2007). 
The solution of the differential equations is executed iteratively with the given boundary conditions employed, and with the use of a modified central difference method. The modifications concern the definition of a variable computational grid. The initial solution resolves the pressure profile for given boundary conditions very quickly, and then the main algorithm adapts the new computational grid according to the second derivatives of the pressure profile, see Figure 3. The second solution to the refined mesh is much more accurate.

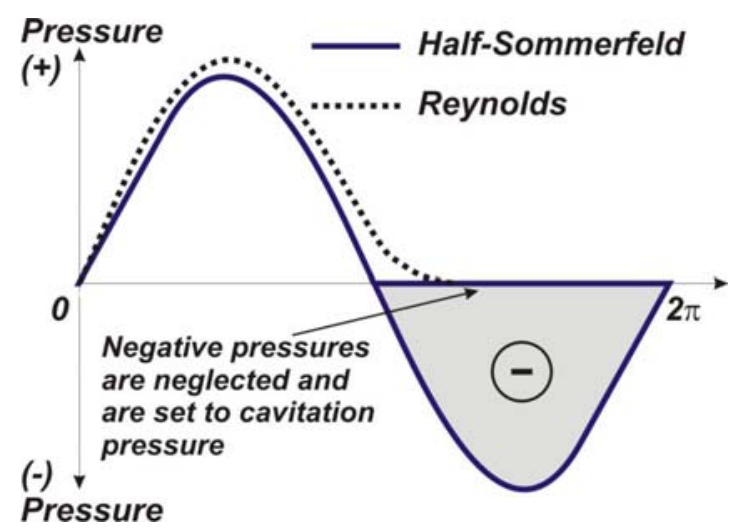

Figure 2: Schematic of cavitation boundary conditions

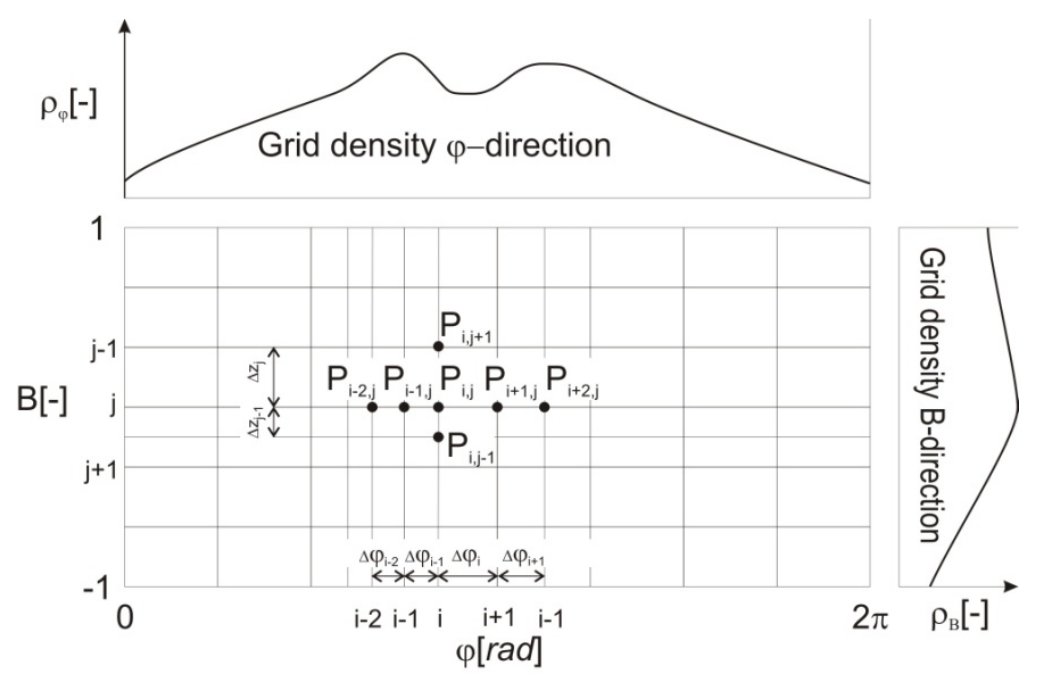

Figure 3: Variable computational grid for slide bearing solution

The results are saved in hydrodynamic databases representing dimensionless bearing reactions (forces and moments) to dimensionless states (eccentricity and tilting value). 


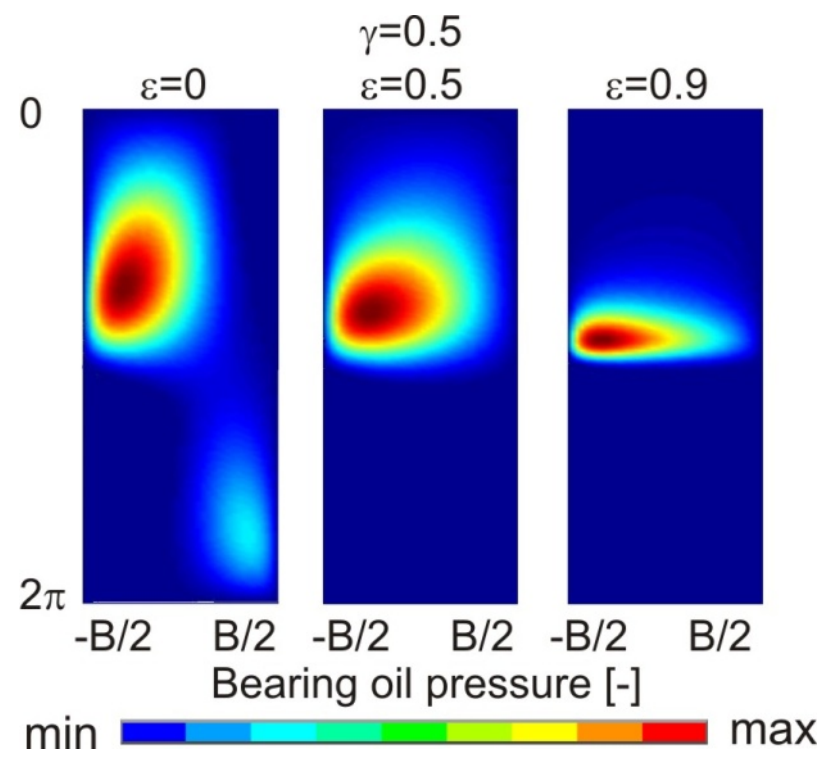

Figure 4: Dimensionless pressure distribution in bearing oil film for a dimensionless journal tilting angle $\gamma=0.5$ and three variants of eccentricities.

During the dynamic solution, MBS Solver subroutines ensure the database access and the necessary analytical steps (coordinate transformations, etc.). Figure 4 shows dimensionless pressure distribution in the bearing oil film for the first tilting angle $\gamma=0.5$ and three variants of relative eccentricities.

\section{RESULTS DISCUSSION}

Failures, and in particular the fatigue fractures, used to occur in connection with an increase in engine power, and with material savings. The fractures were not only caused by the forces arising from combustion pressure processes, inertial forces, or incorrect construction. In most cases, they were discovered to be the result of the periodical torsional vibrations of the crankshaft. Traditionally, there are three types of crankshaft vibrations: bending, torsional and axial vibrations. Bending vibrations are caused by periodical forces that operate perpendicularly on the crankshaft axis. These forces are radial and tangential forces on the crankshaft and imbalanced eccentric forces of the cranktrain. The natural frequencies of bending modes are given a free length of the crankshaft between the bearings. Free lengths of crankshaft between two bearings are very small and the natural frequencies of bending modes are high and there are no resonances at an engine speed range. Stiffness of the bearings and the engine block have a large influence on bending natural frequencies. 


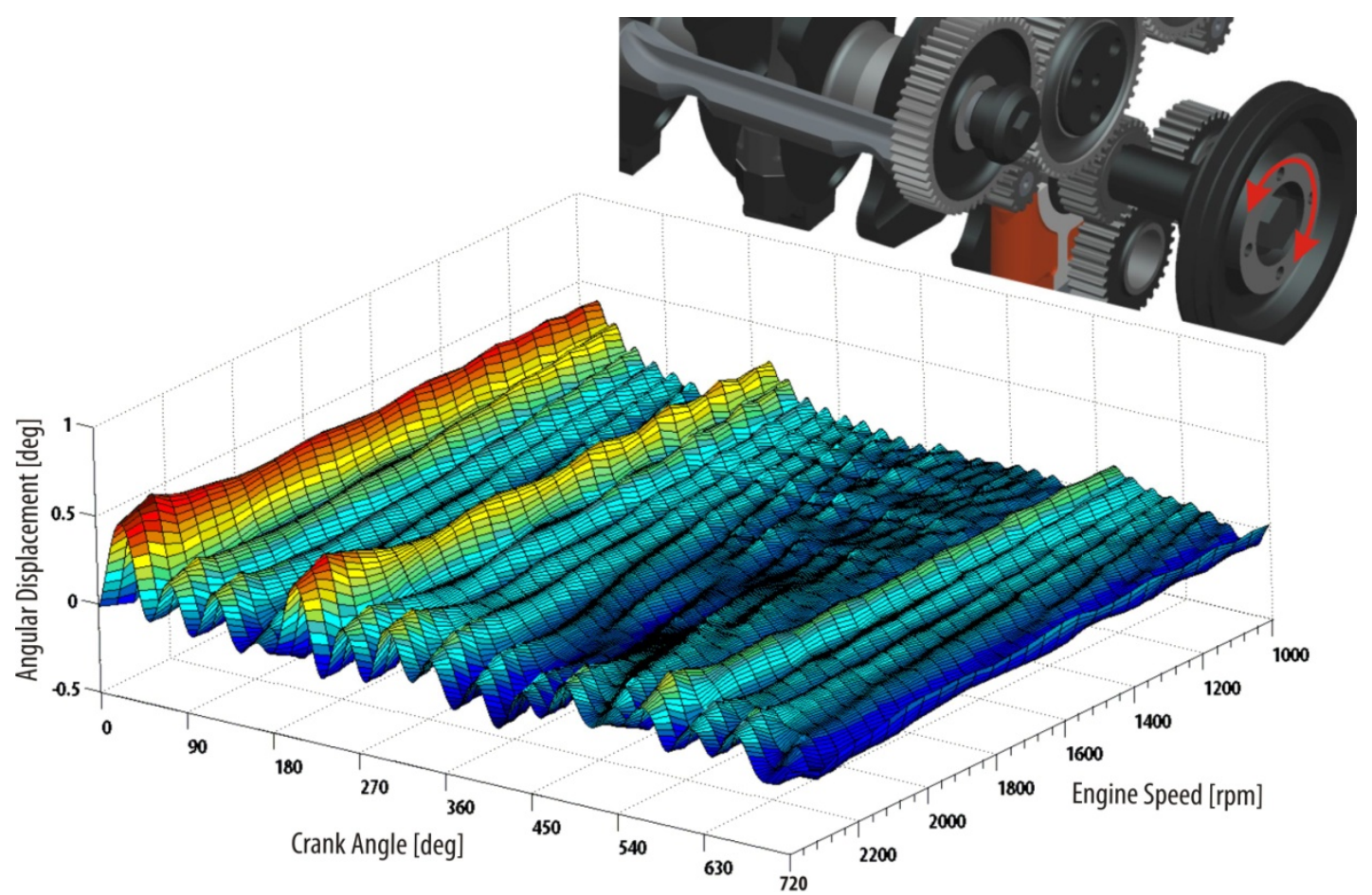

Figure 5: Results of crankshaft torsional vibration analysis in time domain

For most engines, the torsional vibrations of crankshafts are much more dangerous than bending vibrations. The forced torsional vibrations of the crankshaft are caused by timedependent torques. Torsional vibrations reach high values in resonances when the frequency of a forced vibration is equal to the natural frequency. The resonances and relevant critical engine speeds cause an increase in noise and engine vibrations. All vibration types can be obtained from a complex computational model of the cranktrain.

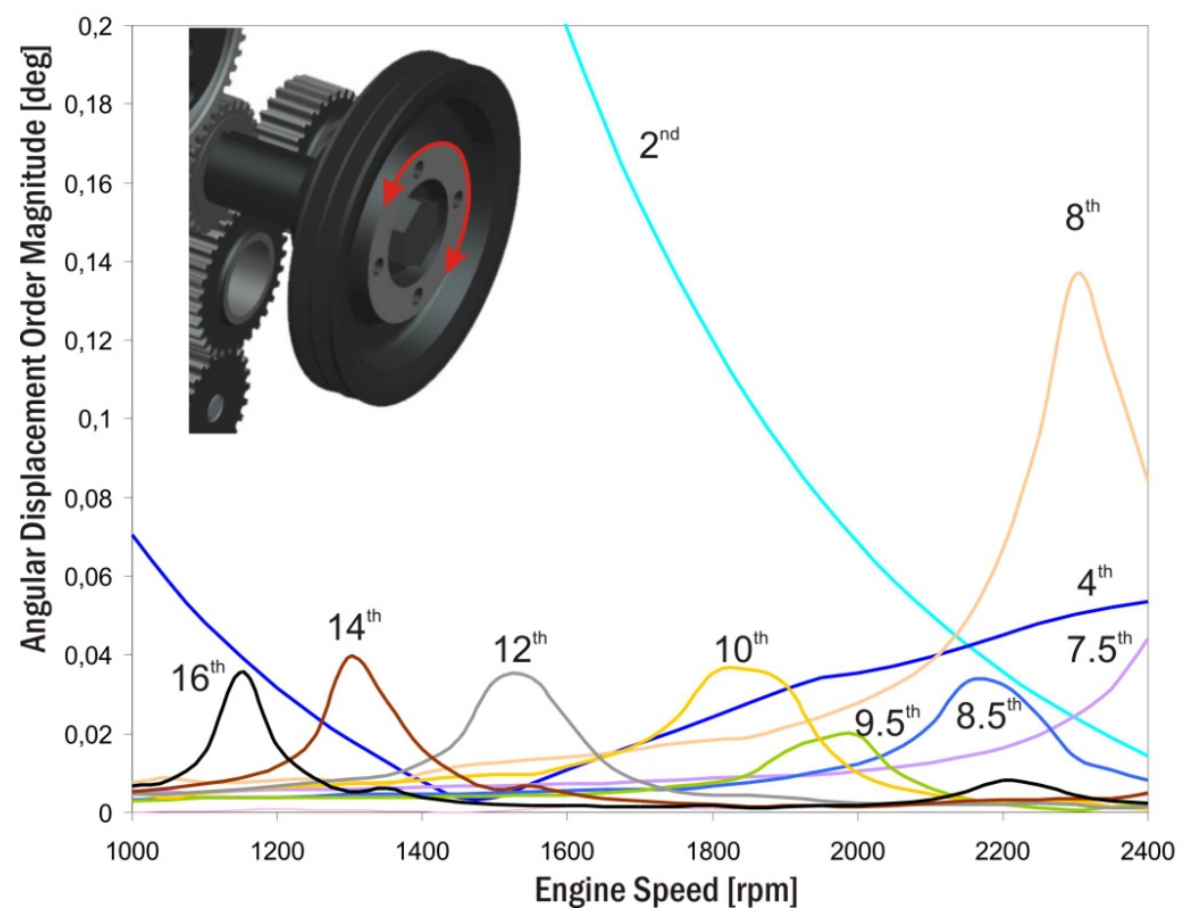

Figure 6: Results of crankshaft torsional vibration analysis in frequency domain 
The results of the vibration analysis are shown in Figures 5 and 6 . They present the results of the torsional vibration order analysis of the in-line four-cylinder diesel engine cranktrain without a damper vs. the engine speed in time and frequency domain.

\section{CONCLUSION}

Multi-body dynamics, with flexible effects such as torsional or bending vibrations of a crankshaft, applied to compute cranktrain dynamics of the engine has enabled an improvement in the NVH behaviour of the engine in the concept phase.

There are further areas for future research and development. They will focus on the quick EHD method - to capture local bearing deformation which is represented by a combination of elastic mode shapes coupled with a fluid film model.

\section{ACKNOWLEGMENT}

The problems mentioned above are being solved within the framework of the project No. 101/06/P032 by the Grant Agency of the Czech Republic. The authors would like to thank GA CR for the rendered assistance.

\section{REFERENCES}

Booker, J., F. Dynamically Loaded Journal Bearings: Mobility Method of Solution. Journal of Basic Engineering. Transaction of ASME. September 1976.

Booker, J., F. Dynamically Loaded Journal Bearings: Numerical Application of Mobility Method. Journal of Lubrication Technology. Transaction of ASME. January, 1971.

Butenschön, H.-J. Das hydrodynamische, zylindrische Gleitlager endlicher Breite unter instationärer Belastung. Dissertation, Universität Karlsruhe 1976.

Du, I. Simulation of Flexible Rotating Crankshaft with Flexible Engine Block and Hydrodynamic Bearing for a V6 Engine. Noise and Vibration Conference. Traverse City, Michigan, May, 1999.

Goenka, P.,K., Booker, J., F. Effect of Surface Ellipticity on Dynamically Loaded Cylindrical Bearings. Journal of Lubrication Technology. Vol. 105. 1983.

Goenka, P.,K., Oh, K., P. A Short Bearing Theory for the Elastohydrodynamic Solution of Journal Bearings. Transactions of the ASME. Journal of Tribology. Volume 108, 1986.

Novotny, P. Cranktrain dynamics simulation - central module of virtual engine, Ph.D.Thesis, Brno University of Technology, 2005, ISSN 1213-4198.

Oujja, R. A new method for cavitations approximation in some general lubrication devices. Applied Mathematics and Computation 181. Elsevier, 2006.

Rebbert, M. Simulation der Kurbewellendynamik unter Berücksichtigung der hydrodynamischen Lagerung zur Lösung motorakusticher Fragen, Ph.D. Thesis, Fakultät für Maschinenwesen der Rheinisch-Westfälischen Technischen Hochschule Aachen, 2000.

Sahlin, F., Almquist, A. A cavitation algorithm for arbitrary lubricant compressibility. In Tribology International 40. Elsevier, 2007.

Thomas, S. Analyse des Betriebsverhaltens von Kurbelwellengleitlagern mittels TEHDBerechnungen. Dissertation. Aachen, Germany, September 2007.

Wei, T., Resh, W. CFD Simulation of Connecting Rod Bearing Lubrication. 2003 SAE World Congress, Detroit, Michigan, 2003. 